\title{
Cesarean section scar pregnancy
}

\author{
Waheeb Naser ${ }^{1}$, Ibrahim A. Abdelazim, ${ }^{1,2}$, Mohannad Abu-Faza' \\ 'Department of Obstetrics and Gynecology, Ahmadi Hospital, KOC, Kuwait \\ 2Department of Obstetrics and Gynecology, Ain Shams University, Egypt
}

\begin{abstract}
Introduction: Cesarean section scar pregnancy (CSSP) occurs due to implantation of the gestational sac over the previous cesarean section or hysterotomy scars.

Case description:

A 40-year-old woman referred to our hospital with a missed period for 5 weeks +3 days, mild vaginal spotting and $\beta$-hCG $5770 \mathrm{mIU} / \mathrm{ml}$ as a case of ectopic pregnancy. The repeated $\beta$-hCG was $8797 \mathrm{mIU} / \mathrm{ml}$ and the transvaginal ultrasound (TVS) showed the gestational sac located in the lower anterior quadrant of the uterus behind the urinary bladder (only a thin layer of myometrium separating it from the bladder), close to the internal cervical os and the site of the previous scars. The case was diagnosed as CSSP and managed according to the hospital protocol by systemic multi-dose methotrexate (MTX) with follow-up using $\beta$-hCG, TVS and complete blood count (CBC). When the $\beta$-hCG result was found to be $60.66 \mathrm{mIU} / \mathrm{ml}$, and the repeated weekly TVS showed a progressive decrease in the size of the gestational sac, the studied woman was discharged from the hospital for follow-up in the outpatient department (OPD).

Conclusions: There is no single best treatment to terminate the CSSP, and the procedure with the fewest complications should be selected. Several authors support systemic multi-dose MTX treatment for CSSP with follow-up using TVS, $\beta$-hCG and CBC.

Key words: cesarean, scar, pregnancy.
\end{abstract}

Corresponding author: Prof. Ibrahim A. Abdelazim, Ain Shams University, Cairo, Egypt and Ahmadi Hospital, Kuwait Oil Company (KOC), Kuwait, P.O. box: 9758, 61008 Ahmadi, Kuwait, phone: +965-66551300, e-mail: dr.ibrahimanwar@ gmail.com 


\section{Introduction}

Cesarean section scar pregnancy (CSSP) is not a type of ectopic pregnancy. Compared to ectopic pregnancies, the CSSP is intrauterine pregnancy and if not terminated, it may result in a live offspring [1].

Cesarean section scar pregnancy occurs due to implantation of the gestational sac over the previous cesarean section or hysterotomy scars [2], followed by erosion of the scar by the chorionic tissue with subsequent uterine rupture and internal hemorrhage [3].

The true incidence of CSSP is estimated as 1 in 1800 to 1 in 2500 of all cesarean deliveries performed $[4,5]$.

Previous cesarean delivery is the only risk factor for CSSP and the incidence of CSSP has increased due to the increased rates of cesarean deliveries and the improved ultrasound diagnostic tools [6].

The CSSP diagnosis is challenging for the obstetrician, because the misdiagnosis rate of CSSP at first consultation is as high as 76\% [7] and CSSPs are often misdiagnosed as "inevitable abortions" "ectopic pregnancies" and/or "cervical pregnancies” [8].

Timor-Tritsch et al. reported a $44.1 \%$ complication rate with CSSP [9], secondary due to missed CSSP diagnosis and/ or inappropriate treatments for CSSP [8].

In contrast, proper diagnosis and management of CSSP prevent subsequent uterine rupture, internal hemorrhage and emergency hysterectomies [6]. So, this case report represents the importance of early diagnosis and management of CSSP cases.

\section{Case report}

A 40-year-old woman, para 7 (previous 5 cesarean sections and 2 vaginal deliveries), with previous gastric sleeve and previous abdominoplasty, was referred to Ahmadi Hospital, Kuwait (31 January 2018) with a missed period for 5 weeks +3 days, lower abdominal pain, mild vaginal spotting and $\beta$-hCG $5770 \mathrm{mIU} / \mathrm{ml}$ as a case of ectopic pregnancy for further management.

The on-call consultant decided to repeat the $\beta$-hCG again, which was $8797 \mathrm{mIU} / \mathrm{ml}$, and the transvaginal ul- trasound (TVS), which showed a symmetrically enlarged uterus, with the gestational sac located in the lower anterior quadrant of the uterus behind the urinary bladder (only a thin layer of myometrium separating it from the bladder), close to the internal cervical os and the site of the previous cesarean section scars. There was no tenderness on movement of the uterine cervix or free fluid in the pouch of Douglas (POD).

The case was diagnosed as CSSP, discussed in the departmental meeting and managed according to the hospital protocol by systemic multi-dose methotrexate (MTX) after patient's counseling.

A systemic multi-dose MTX regimen was given on days $0,2,6$ and 8 alternating with an active form of folic acid (leucovorin $0.1 \mathrm{mg} / \mathrm{kg}$ ) on days 1, 3, 5 and 7, with follow-up using $\beta$-hCG, TVS and complete blood count (CBC).

On day 4 of the first MTX dose (4 February), the $\beta$-hCG initially increased to $13921 \mathrm{mIU} / \mathrm{ml}$, then dropped significantly to $3081 \mathrm{mIU} / \mathrm{ml} 1$ week later (11 February) and to $256 \mathrm{mIU} / \mathrm{ml}$ in the second week (18 February).

On day 21 ( 3 weeks after the first MTX dose), the $\beta$-hCG was $60.88 \mathrm{mIU} / \mathrm{ml}$, and it was $1.95 \mathrm{mIU} / \mathrm{ml}$ on 6 March (34 days after the first MTX dose) (Table I and Figure 1).

When the $\beta$-hCG result was found to be $60.88 \mathrm{mIU} / \mathrm{ml}$ ( 3 weeks after the first MTX dose), the repeated weekly TVS showed progressive decrease in the size of the gestational sac, disappearance of the yolk sac, and progressive increase in the myometrial thickness between the gestational sac and the urinary bladder, the studied patient was discharged from the hospital for follow-up in the outpatient department (OPD).

Two weeks later in the OPD, the studied woman gave a history of mild vaginal bleeding at home and the repeated TVS showed completely disappeared CSSP sac and the $\beta$-hCG was $1.95 \mathrm{mIU} / \mathrm{ml}$ (34 days after the first MTX dose).

She was advised to avoid further pregnancy for at least 6 months after the MTX treatment and she was counseled about the possibility of CSSP recurrence.

On day 11 of the first MTX dose she developed dropped hematological parameters including hemoglobin to $9 \mathrm{~g} / \mathrm{dl}$, white blood cell count (WBCs) to $2.64 \times 10^{3}$ and platelets to $69 \times 10^{3}$ as a side effect of MTX treatment (bone mar-

Table I. $\beta$-hCG levels of the studied woman (grey marks indicate high $\beta$-hCG levels)

\begin{tabular}{|l|l|l|l|l|}
\hline Date & Time & Results & Units & References \\
\hline 6.03 .2018 & 16.31 & 1.95 & $\mathrm{mlU} / \mathrm{ml}$ & $0-10$ \\
\hline 27.02 .2018 & 9.39 & $12.61 \mathrm{H}$ & $\mathrm{mlU} / \mathrm{ml}$ & $0-10$ \\
\hline 21.02 .2018 & 8.24 & $60.88 \mathrm{H}$ & $\mathrm{mlU} / \mathrm{ml}$ & $0-10$ \\
\hline 18.02 .2018 & 11.00 & $256.2 \mathrm{H} \Delta$ & $\mathrm{mlU} / \mathrm{ml}$ & $0-10$ \\
\hline 13.02 .2018 & 8.50 & $1572 \mathrm{H} \Delta$ & $\mathrm{mlU} / \mathrm{ml}$ & $0-10$ \\
\hline 11.02 .2018 & 8.20 & $3081 \mathrm{H}$ & $\mathrm{mlU} / \mathrm{ml}$ & $0-10$ \\
\hline 4.02 .2018 & 9.14 & $13921 \mathrm{H}$ & $\mathrm{mlU} / \mathrm{ml}$ & $0-10$ \\
\hline 31.01 .2018 & 22.20 & $8797 \mathrm{H}$ & $\mathrm{mlU} / \mathrm{ml}$ & $0-10$ \\
\hline
\end{tabular}




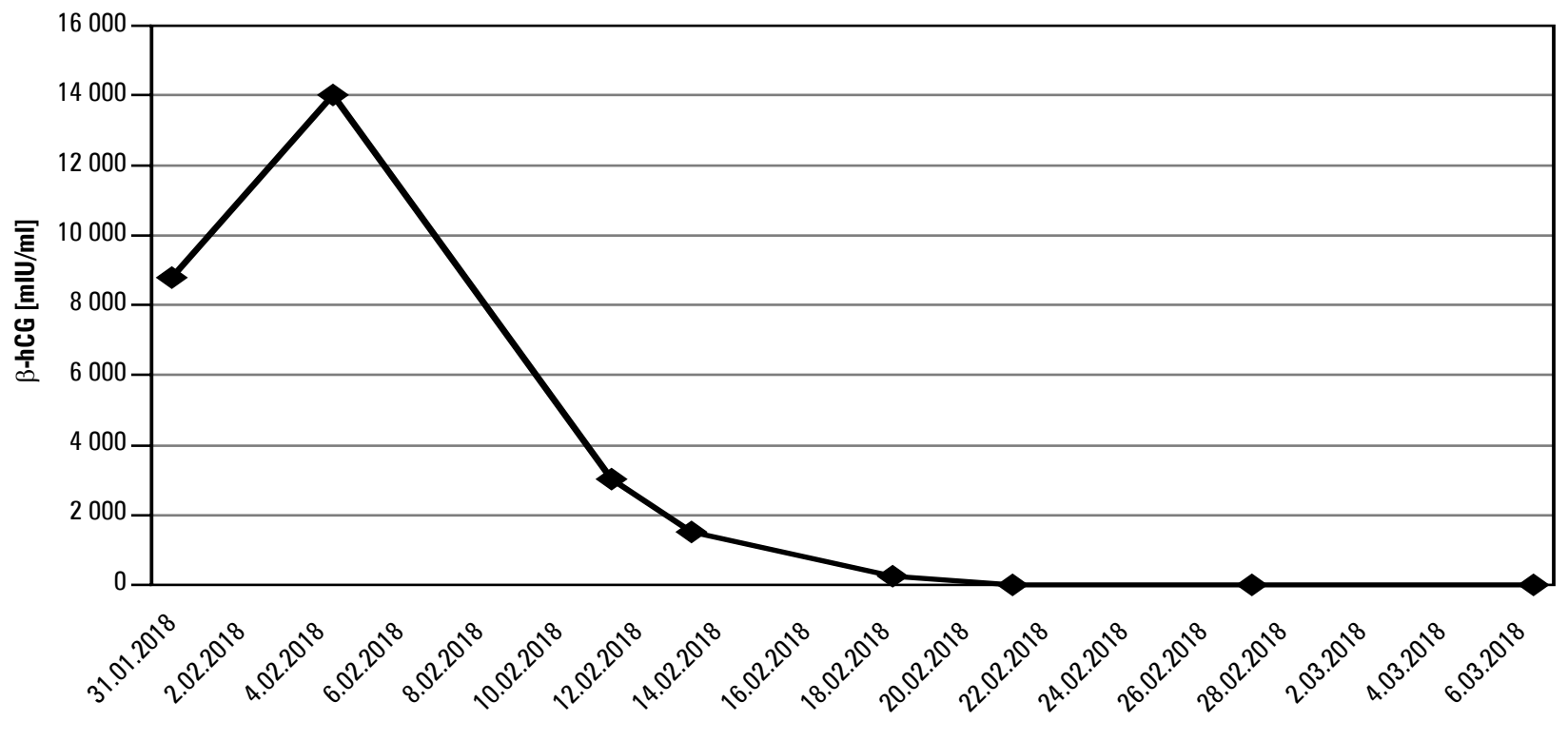

Figure 1. Timeline for $\beta$-hCG levels of the studied patient

row depression). In addition, she developed stomatitis and mouth ulcers managed by a multidisciplinary team approach (hematologists and obstetricians) who advised transfusion of one unit of blood to correct the anemia and leucopoenia and to avoid critical infection. One unit of blood was transfused as advised by the multidisciplinary team and 7 days later (18 February), the patient's hematological parameters significantly improved (hemoglobin increased to $10.4 \mathrm{~g} / \mathrm{dl}$, WBCs to $4.55 \times 10^{3}$ and the platelets to $307 \times 10^{3}$ ).

\section{Discussion}

The diagnosis of CSSP should be based on previous cesarean delivery, positive pregnancy test and the following sonographic criteria [8,9]: 1) Empty uterine cavity and closed, empty endo-cervical canal. 2) Location of the gestational sac in lower anterior quadrant of the uterus, behind the urinary bladder (separated from the urinary bladder by a thin layer of the myometrium), close to the internal cervical os and the site of the previous cesarean section or hysterotomy scar (Figure 2), with or without fetal pole and/or yolk sac (Figure 3), with or without heart beats (depending

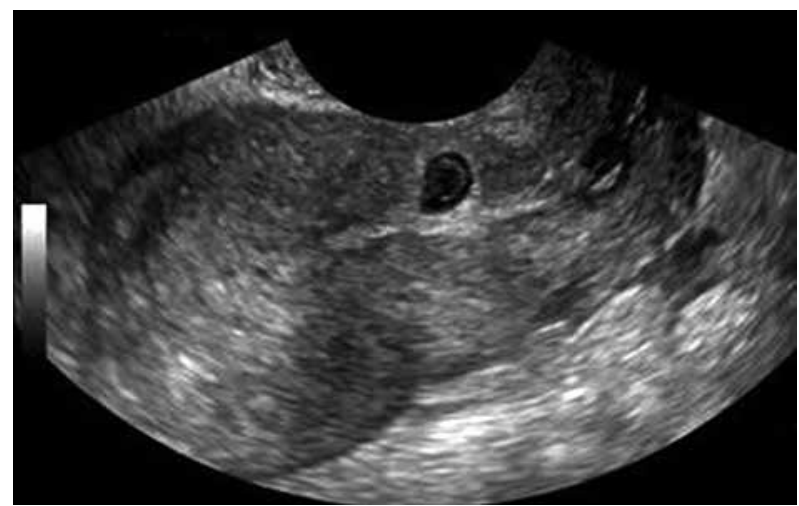

Figure 3. Gestational sac with yolk sac inside and thin myometrium between the sac and the bladder.

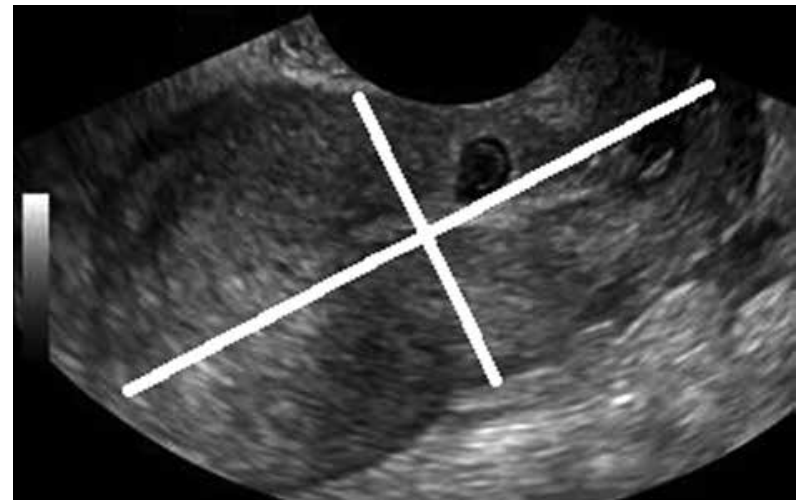

Figure 2. Cesarean section scar pregnancy

on the gestational age). 3) Absence or presence of thin myometrial layer between the gestational sac and the urinary bladder wall (Figure 4). 4) Numerous blood vessels and arterio-venous malformation (AVM) around the gestational sac "marking" the site of the placental implantation (Figure 4).

The first step during evaluation of CSSP is to determine if there is fetal heart activity, followed by patient's counseling

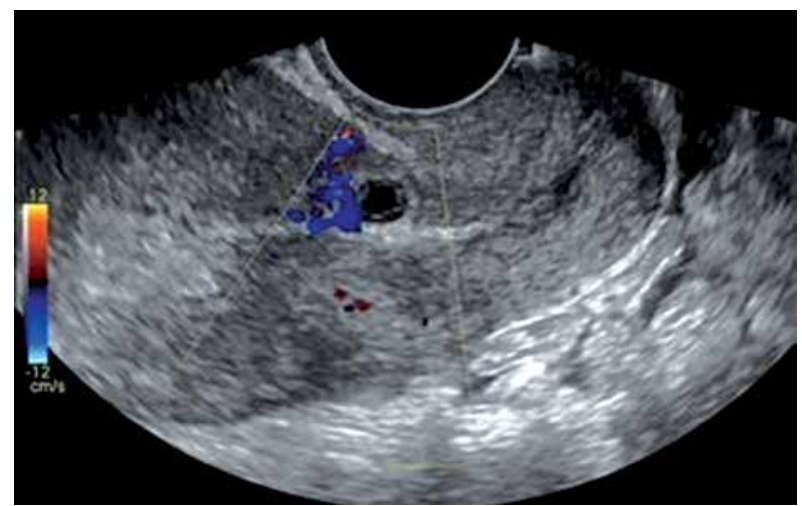

Figure 4. Numerous blood vessels surrounding the cesarean section scar pregnancy 
$[8,9] .1)$ If there is no cardiac activity, re-examine every $2-3$ days. If there is still no documented heart activity and no yolk sac and/or embryo, the ultrasound and biochemical follow-up are sufficient until the serum $\beta$-hCG value returns to zero \pm intramuscular (IM) methotrexate (MTX) (even if no heart activity is observed) may be a reasonable treatment option $[8,9] .2)$ There are two options if there is positive fetal cardiac activity: either termination or continuation of the pregnancy. If a patient decides to continue her pregnancy, the physician should counsel the patient about the risks of hemorrhage, uterine rupture, need for a repeat cesarean delivery, morbid adherent placenta (MAP) and emergency puerperal hysterectomy $[8,9] .3$ ) The risk of a recurrent CSSP is estimated to be about $1 \%$ [10].

Treatment should be individualized based on the patient's age, number of children and the clinician's experience.

The following treatments for CSSP have been suggested: 1) Major surgical approaches: laparotomy (hysterectomy or local excision), laparoscopic or hysteroscopic excision, suction aspiration followed by balloon compression to stop the bleeding (vaginal route of evacuation guided by real-time ultrasound). 2) Minimally invasive surgery: local intra-gestational injection of MTX [11]. 3) Systemic medication as single or multi-dose MTX [12].

Suction aspiration is the traditional choice, but it exposes vessels to injury and the surgeon should be ready for major bleeding which necessitates hysterectomy or balloon compression and blood transfusion. Inserting and inflating a Foley's balloon catheter at the site of the CSSP with 5 to $30 \mathrm{ml}$ is a new and potentially extremely useful adjunct treatment approach. Catheters can be kept in situ for 3-4 days with antibiotic coverage [13-14].

Metotrexate is the most commonly used treatment for CSSP: systemic single dose $1 \mathrm{mg} / \mathrm{kg}$ of body weight or $50 \mathrm{mg} / \mathrm{m}^{2}$ of body surface area [11]; or systemic multi-dose regimen MTX alternating with active form or folic acid (leucovorin) to avoid bone marrow depression [12]. Ultrasound-guided intra-gestational MTX is the most effective treatment for CSSP between 6 and 8 weeks' gestation as it stops cardiac activity immediately and should be considered if the patient desires future fertility $[15,16]$.

Wang et al. concluded that uterine artery embolization (UAE) with local and MTX treatment (UAE-MTX) or ultrasound-guided local and systemic MTX treatment (USGMTX) were similarly effective in treating CSSP and both treatment modalities are likely to fail for CSSP patients with the gestational $\mathrm{sac}>5 \mathrm{~cm}$ [17].

Combined hysteroscopic and laparoscopic excision of CSSP was reported in treatment of 113 cases with a reasonably low complication rate of $18.4 \%$, compared with other methods [18-22].

Excision of CSSP by laparotomy was reported in approximately 15 cases followed by repair of the uterus if future fertility is desired [23]. Elective hysterectomy was performed to treat bleeding complications of CSSP [24].

The studied case showed on day 4 of the first MTX dose an initial increase of $\beta$-hCG to $13921 \mathrm{mIU} / \mathrm{ml}$, which dropped significantly to $3081 \mathrm{mIU} / \mathrm{ml} 1$ week later and to
$256 \mathrm{mIU} / \mathrm{ml}$ in the second week, and the treating team may be discouraged by the initial increase of $\beta$-hCG after multi-dose MTX treatment for CSSP.

However, several authors support a systemic multi-dose intramuscular (IM) MTX regimen for CSSP with ultrasound and biochemical follow-up until the serum $\beta$-hCG value returns to zero (even if no heart activity is observed) $[8,9]$.

In addition, the $\beta$-hCG may take up to $35-40$ days (6 weeks) to reach the non-pregnant level after the multi-dose MTX regimen for CSSP [25].

Uludag et al. compared the use of systemic and local methotrexate in the treatment of CSSP and they found that the mean times for $\beta$-hCG normalization and the uterine mass disappearance were significantly shorter in the local MTX group than in the systemic MTX group (6.17 \pm 1.55 vs. $8.11 \pm 2.0$ weeks, $p=0.001$ and $10.47 \pm 4.14$ vs. $13.40 \pm 4.44$ weeks, $p=0.002$; respectively) [25].

The studied patient developed stomatitis and mouth ulcers with a drop of her hemoglobin to $9 \mathrm{~g} / \mathrm{dl}$, WBCs to $2.64 \times 10^{3}$ and platelets to $69 \times 10^{3}$ as a side effect of MTX treatment, which was managed by a multidisciplinary team (hematologists and obstetricians) who advised transfusion of one unit of blood to correct the anemia and leucopenia and avoid critical infection.

Uludag et al. found that oral ulcers were the most common side effect seen in seven patients treated with systemic MTX for CSSP [25].

The issue of hospitalization or outpatient treatment of CSSP cases is discussed for the first time in this case presentation, and this issue should be decided by the treating team after the patient's counseling, especially if there is susceptibility to bleeding attacks or bone marrow depression (in cases treated with a systemic multi-dose MTX regimen).

\section{Conclusions}

There is no single best treatment to terminate the CSSP, and the procedure with the fewest complications should be selected. Suction aspiration is the traditional choice, but it exposes vessels to injury which necessitates hysterectomy or balloon compression. Systemic single-dose MTX has a questionable effect as first-line therapy. Several authors support a systemic multi-dose MTX regimen for CSSP with ultrasound with biochemical follow-up until the serum $\beta$-hCG value returns to zero (even if no heart activity is observed). UAE-MTX and USG-MTX were similarly effective in treating CSSP and both treatment modalities are likely to fail with gestational sac $>5 \mathrm{~cm}$.

\section{Acknowledgments}

The authors are grateful to the woman who agreed to participate in this case report.

\section{Conflict of interest}

The authors declare no conflict of interest. 


\section{References}

1. Timor-Tritsch IE, Monteagudo A, Santos R, Tsymbal T, Pineda G, Arslan AA. The diagnosis, treatment, and follow-up of cesarean scar pregnancy. Am J Obstet Gynecol 2012; 207: 44.e1-13.

2. Elito Júnior J, Araujo Júnior E, Martins Santana EF, et al. Uterine artery embolization with methotrexate infusion as treatment for cesarean scar pregnancy. Case report. Med Ultrason 2013; 15: 240-3.

3. Gao L, Huang Z, Zhang X, Zhou N, Huang X, Wang X. Reproductive outcomes following cesarean scar pregnancy: a case series and review of the literature. Eur J Obstet Gynecol Reprod Biol 2016; 200: 102-7.

4. Jurkovic D, Hillaby K, Woelfer B, Lawrence A, Salim R, Elson CJ. Cesarean scar pregnancy. Ultrasound Obstet Gynecol 2003; 21 : 220-7.

5. Seow KM, Hwang JL, Tsai YL, Huang LW, Lin YH, Hsieh BC. Subsequent pregnancy outcome after conservative treatment of a previous cesarean scar pregnancy. Acta Obstet Gynecol Scand 2004; 83: 1167-72.

6. Fu LP. Therapeutic approach for the cesarean scar pregnancy. Medicine (Baltimore) 2018; 97: e0476.

7. Jurkovic D, Hillaby K, Woelfer B, Lawrence A, Salim R, Elson CJ. First-trimester diagnosis and management of pregnancies implanted into the lower uterine segment Cesarean section scar. Ultrasound Obstet Gynecol 2003; 21: 220-7.

8. Timor-Tritsch IE, Monteagudo A, Cali G, et al. Cesarean scar pregnancy is a precursor of morbidly adherent placenta. Ultrasound Obstet Gynecol 2014; 44: 346-53.

9. Timor-Tritsch IE, Monteagudo A. Unforeseen consequences of the increasing rate of cesarean deliveries: early placenta accreta and cesarean scar pregnancy. A review. Am J Obstet Gynecol 2012; 207: 14-29.

10. Gupta S, Pineda G, Rubin S, Timor-Tritsch IE. Four consecutive recurrent cesarean scar pregnancies in a single patient. J Ultrasound Med 2013; 32: 1878-80.

11. Yin XH, Yang SZ, Wang ZQ, Jia HY, Shi M. Injection of MTX for the treatment of cesarean scar pregnancy: comparison between different methods. Int J Clin Exp Med 2014; 7: 1867-72.

12. Kutuk MS, Uysal G, Dolanbay M, Ozgun MT. Successful medical treatment of cesarean scar ectopic pregnancies with systemic multidose methotrexate: single-center experience. J Obstet Gynaecol Res 2014; 40: 1700-6.

13. Wang DB, Chen YH, Zhang ZF, et al. Evaluation of the transvaginal resection of low-segment cesarean scar ectopic pregnancies. Fertil Steril 2014; 101: 602-6.

14. Wang Z, Shan L, Xiong H. Transvaginal removal of ectopic pregnancy tissue and repair of uterine defect for cesarean scar pregnancy. Clin Exp Obstet Gynecol 2013; 40: 546-7.

15. Seow KM, Wang PH, Huang LW, Hwang JL. Transvaginal sono-guided aspiration of gestational sac concurrent with a local methotrexate injection for the treatment of unruptured cesarean scar pregnancy. Arch Gynecol Obstet 2013; 288: 361-6.

16. Yamaguchi M, Honda R, Uchino K, Tashiro H, Ohba T, Katabuchi H. Transvaginal methotrexate injection for the treatment of cesarean scar pregnancy: efficacy and subsequent fecundity. J Minim Invasive Gynecol 2014; 21: 877-83.
17. Wang M, Yang Z, Li Y, et al. Conservative management of cesarean scar pregnancies: a prospective randomized controlled trial at a single center. Int J Clin Exp Med 2015; 8: 18972-80.

18. Mollo A, Alviggi C, Conforti A, Insabato L, De Placido G. Intact removal of spontaneous twin ectopic Caesarean scar pregnancy by office hysteroscopy: case report and literature review. Reprod Biomed Online 2014; 29: 530-3.

19. Wang G, Liu X, Bi F, et al. Evaluation of the efficacy of laparoscopic resection for the management of exogenous cesarean scar pregnancy. Fertil Steril 2014; 101: 1501-7.

20. Wang YL, Weng SS, Huang WC, Su TH. Laparoscopic management of ectopic pregnancies in unusual locations. Taiwan J Obstet Gynecol 2014; 53: 466-70.

21. Wu X, Xue X, Wu X, et al. Combined laparoscopy and hysteroscopy vs. uterine curettage in the uterine artery embolization-based management of cesarean scar pregnancy: a cohort study. Int J Clin Exp Med 2014; 7: 2793-803.

22. He Y, Wu X, Zhu Q, et al. Combined laparoscopy and hysteroscopy vs. uterine curettage in the uterine artery embolization-based management of cesarean scar pregnancy: a retrospective cohort study. BMC Womens Health 2014; 14: 116.

23. Abdelkader MA, Fouad R, Gebril AH, El Far MA, Elyassergi DF. Caesarean scar pregnancy: hysterotomy is rapid and safe management option. Arch Gynecol Obstet 2014; 290: 381-3.

24. Nankali A, Ataee M, Shahlazadeh H, Daeichin S. Surgical management of the cesarean scar ectopic pregnancy: a case report. Case Rep Obstet Gynecol 2013; 2013: 525187.

25. Uludag SZ, Kutuk MS, Ak M, et al. Comparison of systemic and local methotrexate treatments in cesarean scar pregnancies: time to change conventional treatment and follow-up protocols. Eur J Obstet Gynecol Reprod Biol 2016; 206: 131-5. 